\title{
Comment on "An algorithm for identification and classification of individuals with type I and type 2 diabetes mellitus in a large primary care database", written by Sharma et al
}

\author{
This article was published in the following Dove Press journal: \\ Clinical Epidemiology \\ 25 January 2017 \\ Number of times this article has been viewed
}

\section{Valéry Bocquet}

Competence Center for Methodology and Statistics, Luxembourg Institute of Health, Luxembourg
Correspondence: Valéry Bocquet Competence Center for Methodology and Statistics, Luxembourg Institute of Health, IA-B Rue Thomas Edison, L- 1445 Strassen, Luxembourg

Tel +35226970763

Fax +352 26970717

Email valery.bocquet@lih.lu

\section{Dear editor}

Diabetes is a disease whose global prevalence has been rising year after year, and by 2014 more than 400 million individuals were diagnosed with diabetes. ${ }^{1}$ As a consequence, screening of patients with type 1 or type 2 diabetes has become important, both to estimate the prevalence of diabetes and to treat affected individuals. For that purpose, a two-step algorithm suggested by Sharma et $\mathrm{al}^{2}$ was recently published, whose aims were to identify type 1 or type 2 individuals from a primary care database. The first step of the algorithm was based on the diagnostic records, treatment given, and results obtained from clinical tests. The second part was based on the combination of diagnostic codes, prescribed medications, age at the time of diagnosis, and finally whether the case was prevalent or incident.

I found this article and the associated algorithm all the more interesting in that it shares obvious similarities with an algorithm proposed by Renard et al published in $2011,{ }^{3}$ even though the type of database used to obtain the data was not the same. Five years ago, we suggested an algorithm called Diabecolux to identify patients with diabetes using administrative reimbursement databases. The first step of this algorithm was to select only patients with diabetes and then to distinguish type 1 and type 2 diabetes based on patients' age and the type and number of hypoglycemic agents reimbursed between 1995 and 2006.

As on November 30, 2016, numerous articles with keyterm "diabetes" in their titles have been found to be published in PubMed ( $\mathrm{N}=180,882)$. "Algorithm" is also a term that has been often found, with almost 20,000 publications in the PubMed $(\mathrm{N}=19,196)$ carrying the keyterm "algorithm" in their titles. Moreover, the term "identify" or "identification" has been used in 1,138,089 publications by their authors in the title or abstract. However, a combination of all these terms was found only in 15 publications. It is surprising to note that two articles dealing with the same topic have used such a similar approach with respect to their algorithm, but the most recent article did not mention the first one.

\section{Disclosure}

The author reports no conflicts of interest in this communication.

\section{References}

1. NCD Risk Factor Collaboration (NCD-RisC). Worldwide trends in diabetes since 1980: a pooled analysis of 751 population-based studies with 4.4 million participants. Lancet. 2016;387(10027):1513-1530. 
2. Sharma M, Petersen I, Nazareth I, Coton SJ. An algorithm for identification and classification of individuals with type 1 and type 2 diabetes mellitus in a large primary care database. Clin Epidemiol. 2016;8: $373-380$.
3. Renard LM, Bocquet V, Vidal-Trecan G, Lair ML, Couffignal S, BlumBoisgard C. An algorithm to identify patients with treated type 2 diabetes using medico-administrative data. BMC Med Inform Decis Mak. 2011;11:23. 


\section{Authors' reply \\ Manuj Sharma \\ Irene Petersen \\ Irwin Nazareth \\ Sonia Coton}

Research Department of Primary Care and Population Health, University College London, London, UK

Correspondence: Manuj Sharma

Research Department of Primary Care and Population Health, University College London, Royal Free campus, Rowland Hill Street, London NW3 2PF, UK

Email manuj.sharma.II@ucl.ac.uk

\section{Dear editor}

We thank you very much for bringing your interesting letter to our attention. ${ }^{1}$

Our algorithm ${ }^{2}$ is based largely on the Royal College of General Physicians guidance which made it particularly suitable to UK databases, but similar to the algorithm developed by Renard et al it has sufficient generalizable elements. ${ }^{3}$

As noted, there are indeed some similarities between the algorithms such as the use of age at the time of diagnosis and the analysis of prescribed medication to aid diabetes classification. However, there are several differences as well. One such difference is our use of diagnostic codes for diabetes classification. This helped us eliminate not only gestational diabetes cases but also some rarer forms of diabetes such as latent autoimmune diabetes in adults and maturity-onset diabetes of the young. This ensured a robust classification of type
1 and type 2 diabetes. This use of diagnostic codes was also necessary to exclude women who were prescribed metformin for other reasons such as polycystic ovarian disease. Additionally, the use of hemoglobin A1c diagnostic thresholds in our algorithm ensured that we identified diet-controlled type 2 diabetics as well. These have been estimated to comprise around $30 \%$ of all type 2 diabetics and we wanted to ensure this was captured to avoid an underestimate of the incidence and prevalence of type 2 diabetes. ${ }^{4}$ We appreciate that the authors of the study led by Renard et al did not have access to diagnostic data or $\mathrm{HbA} 1 \mathrm{c}$ to allow this to be undertaken. Hence, their focus was on treated type 2 diabetes patients.

We hope this helps to clarify the similarities and differences between the two algorithms.

\section{Disclosure}

The authors report no conflicts of interest in this communication.

\section{References}

1. Renard LM, Bocquet V, Vidal-Trecan G, Lair ML, Couffignal S, BlumBoisgard C. An algorithm to identify patients with treated type 2 diabetes using medico-administrative data. BMC Med Inform Decis Mak. 2011;11:23.

2. Sharma M, Petersen I, Nazareth I, Coton SJ. An algorithm for identification and classification of individuals with type 1 and type 2 diabetes mellitus in a large primary care database. Clin Epidemiol. 2016;8:373-380.

3. Royal College of General Practitioners. Coding, Classification and Diagnosis of Diabetes. 2011. Available from: http://www.sdrn.org.uk/ sites/sdrn.org.uk/files/nhs\%20diagnosis\%20classification\%20report. pdf. Accessed June 6, 2015

4. Hippisley-Cox J, Pringle M. Prevalence, care, and outcomes for patients with diet-controlled diabetes in general practice: cross sectional survey. Lancet. 2004;364(9432):423-428.

Dove Medical Press encourages responsible, free and frank academic debate. The content of the Clinical Epidemiology 'letters to the editor' section does not necessarily represent the views of Dove Medical Press, its officers, agents, employees, related entities or the Clinical Epidemiology editors. While all reasonable steps have been taken to confirm the content of each letter, Dove Medical Press accepts no liability in respect of the content of any letter, nor is it responsible for the content and accuracy of any letter to the editor.

Clinical Epidemiology

\section{Publish your work in this journal}

Clinical Epidemiology is an international, peer-reviewed, open access, online journal focusing on disease and drug epidemiology, identification of risk factors and screening procedures to develop optimal preventative initiatives and programs. Specific topics include: diagnosis, prognosis, treatment, screening, prevention, risk factor modification,

Submit your manuscript here: https://www.dovepress.com/clinical-epidemiology-journal
Dovepress

systematic reviews, risk and safety of medical interventions, epidemiology and biostatistical methods, and evaluation of guidelines, translational medicine, health policies and economic evaluations. The manuscript management system is completely online and includes a very quick and fair peer-review system, which is all easy to use. 